\title{
ĐÁNH GIÁ ẢNH HƯởNG LÊN TUẦN HOÀN, HÔ HẤP VÀ MỘT Số TÁC DUUNG KHÔNG MONG MUỐN CỦA GIẢM ĐAU SAU MỔ CẮT TỬ CUNG HOÀN TOÀN ĐƯờNG BUUNG BẰNG GÂY TÊ MĂT PHẲNG CƠ NGANG BỤNG DƯớI HƯớ'NG DẪN CỦA SIÊU ÂM
}

\section{TÓM TẮT}

Mục tiêu: Đánh giá ảnh hưởng lên tuân hoàn, hô hấp và một số tác dụng không mong muốn khác của giảm đau sau mổ cắt tử cung hoàn toàn đường bụng bằng phương pháp gây tê mặt phẳng cơ ngang bụng (TAP block) với ropivacain 0,25\% dưới hướng dân của siêu âm. Đối tượng, phương pháp: 60 bệnh nhân được phẫu thuật cắt tử cung hoàn toàn đướng bụng, vô cảm bằng gây tê tủy sống, sau mổ được phân bố ngẫu nhiên vào hai nhóm giảm đau sau mổ bằng 2 phương pháp: Nhóm nghiên cứu, bệnh nhân được gây tê mặt phẳng cơ ngang bụng dưới hướng dẫn cửa siêu âm sử dụng $0,75 \mathrm{mg} / \mathrm{kg}$ ropivacain $0,25 \%$ mối bên (nhóm TAP) sau đó phối hợp với PCA morphin tĩnh mạch. Nhóm chứng là nhóm không được gây tê TAP block để giảm đau mà chỉ sử dụng PCA morphin tĩnh mach đơn thuần (nhóm chứng). Các thông số nghiên cứu được theo dõi liên tục 24 giờ đầu sau mổ gồm: Ảnh hưởng đến tuần hoàn và hô hấp, độ an thần, nôn, buồn nôn, bí tiểu, ngứa.... Kết quả: Không có sự khác biệt về các chỉ số tuần hoàn, hô hấp của các bệnh nhân ở hai nhóm. Tỷ lệ nôn, buồn nôn của nhóm TAP block thấp hơn có ý nghĩa so với nhóm chứng $(13,33 \%$ so với $30 \% ; p<0,05)$. Tỷ lệ bệnh nhân có mức an thần độ I, II của nhóm TAP block cũng thấp hơn có ý nghĩa so với nhóm chứng (30\% so với 63,3\%). Tỷ lệ ngứa, bí tiểu không có sự khác biệt giữa hai nhóm (3,3\% và $6,7 \%$ so với $6,7 \%$ và $6,7 \%)$. Kết luận: Gây tê mặt phẳng cơ ngang bụng hai bên bằng ropivacain $0,25 \%$, dưới hướng dấn của siêu âm không ảnh hưởng đến tuần hoàn, hô hấp của bệnh nhân nhưng làm giảm tỷ lệ nôn, buồn nôn và tỷ lệ an thần độ I, độ II so với nhóm chứng.

Tư khóa: Phẫu thuật cắt từ cung hoàn toàn đường bụng, TAP block, Ropivacain, tác dụng không mong muốn.

\section{SUMMARY \\ EVALUATE THE EFFECTS ON CIRCULATION, ON RESPIRATION AND SOME OTHER SIDE EFFECTS OF UNTRASOUND GUIDED TRANSVERSUS ABDOMINIS PLANE BLOCK AFTER TOTAL ABDOMINAL HYSTERECTOMY}

\footnotetext{
${ }^{1}$ Trường Đại học Y Hà Nội.

${ }^{2}$ Bệnh viện Hữu Nghị Đa khoa Nghệ An Chịu trách nhiệm chính: Nguyễn Đức Lam Email: lamgmhs75@gmail.com Ngày nhận bài: 28.12.2020 Ngày phản biện khoa học: 16.2.2021 Ngày duyệt bài: 26.2.2021
}

\section{Nguyễn Đức Lam 1 , Võ Thế Trung ${ }^{2}$}

Objective: To evaluate the effects on circulation, on respiration and some other side effects of Ultrasound guided transversus abdominis plane (TAP) block after total abdominal hysterectomy with ropivacaine $0.25 \%$. Mthods: 60 patients with spinal anesthesia underwent total abdominal hysterectomy were randomly divided in two groups: Treatment group getting ultrasound guided TAP block with 0.75 $\mathrm{mg} / \mathrm{kg}$ of ropivacaine $0.25 \%$ in both sides combined with intravenous morphine PCA at the end of surgery, and control group had not received TAP block for pain relief and used only IV morphine PCA alone (control group). We continuously recorded mean blood pressure, heart rate, respiratory rate, sedation, nausea, vomiting, urinary retention, pruritus... during the surgery and for the first 24 hours after surgery. Results: There was no difference in circulatory and respiratory parameters of patients in the two groups. The rates of nausea and vomiting of the TAP block group were significantly lower than the control group $(13.33 \%$ versus $30 \%$; $p<0.05)$. The rate of sedation level I and II of the TAP block group was also significantly lower than the control group (30\% versus $63.3 \%)$. The rates of pruritus and urinary retention did not differ between the two groups (3.3\% and $6.7 \%$ and $6.7 \%$ versus $6.7 \%$ and $6.7 \%$ ). Conclusions: Bilateral untrasound guided TAP block with ropivacaine $0.25 \%$, did not affect on the patient's circulation and respiration but reduced the rate of vomiting, nausea and sedation level I, level II compared with the control group.

Keywords: Total Abdominal Hysterectomy TAP block, Ropivacaine, side effects.

\section{I.ĐăT VẤN ĐỀ}

Gây tê mặt phẳng cơ ngang bụng (Transverse Abdominis Plane Block) viết tắt là TAP block là kỹ thuật đưa một lượng thuốc tê tâp trung vào mặt phẳng giữa cơ ngang bụng và cơ chéo bụng trong nới các nhánh thần kinh chi phối cảm giác cho vùng thành bụng ${ }^{1}$. Trên thế giới có nhiêu nghiên cứu về phương pháp gây tê TAP block để giảm đau sau mổ và ngày càng được áp dụng rộng rãi như là một phần của giảm đau đa mô thức, đem lại hiệu quả giảm đau tốt, giảm tiêu thụ và tác dụng phụ của opioid. Tại Việt Nam hiện tại chưa có nhiều nghiên cứu về sử dụng phương pháp TAP block để giảm đau sau mồ cắt tử cung hoàn toàn bằng đường bụng, đặc biệt chưa đánh giá được các tác dụng không mong muốn của phương pháp này. Vì vậy chúng tôi 
tiến hành nghiên cứu nhằm mục tiêu: "Đánh giá một số tác dụng không mong muốn của giảm đau sau mồ cắt tử cung hoàn toàn đường bụng bằng gây tê mặt phẳng cơ ngang bụng hai bên bằng Ropivacain 0,25\% dưới hướng dẫn siêu âm".

\section{II. ĐỐI TƯợNG VÀ PHƯƠNG PHÁP NGHIÊN CỨU}

\section{1. Đối tượng nghiên cứu}

Tiêu chuẩn lưa chon: Các bênh nhân có chỉ định phẫu thuật cắt tử cung hoàn toàn đường bụng, được mổ theo đường ngang trên vệ (đường mổ Pfannenstiel). ASA I, II tuổi từ 18 60 tuổi.

Tiêu chuẩn loại trừ: Có bệnh lý đau mạn tính thường xuyên phải sử dụng thuốc giảm đau. Đang dùng thuốc giảm đau họ opiod hoặc thuốc IMAO ngay trước mổ. Có chống chỉ định của gây tê thân kinh, dị ứng thuốc tê. BN được chẩn đoán ung thư tử cung hoặc ung thư buồng trứng.

\section{Phương pháp nghiên cứu}

Thiết kế nghiên cứu: Nghiên cứu thử nghiệm lâm sàng, ngẫu nhiên có đối chứng.

Địa điểm, thời gian nghiên cứu: Tại khoa Gây mê Hồi sức, Bệnh viện phụ sản Hà Nội từ 8/2019 đến tháng 8/2020.

Cỡ mẫu: 60 bệnh nhân chia đều làm 2 nhóm.

Chọn mẫu: Phân nhóm bằng bốc thăm ngẫu nhiên. Nhóm 1 (Nhóm chứng) $\mathrm{n}_{1}=30$ : Bệnh nhân sẽ được giảm đau sau mổ sử dụng thuốc morphine tĩnh mạch theo phương pháp bệnh nhân tự điều khiển (PCA). Nhóm 2 (Nhóm TAP) $\mathrm{n}_{2}=30$ : Bệnh nhân sẽ được giảm đau sau mổ bằng gây tê mặt phẳng cơ ngang bụng dưới hướng dẫn của siêu âm kết hợp sử dụng thuốc morphine tĩnh mạch theo phương pháp bệnh nhân tự kiểm soát.

Các bước tiến hành: Các bênh nhân cả hai nhóm đều được gây tê tủy sống bằng bupivacain $(10 \mathrm{mg})$ và fentanyl $(30 \mathrm{mg})$ ở L2-3 để vô cảm trong mổ. Sau mổ bênh nhân được bốc thăm ngẫu nhiên để chia thành hai nhóm được giảm đau sau mổ bằng hai phương pháp khác nhau: Nhóm chứng chuẩn độ rồi lắp PCA morphine tĩnh mạch với $1 \mathrm{ml} / 1 \mathrm{mg}$, bolus $1 \mathrm{ml}$, thời gian khóa 8 phút, liêu tối đa $30 \mathrm{ml} / 4$ giờ. Nhóm TAP được gây tê TAP block dưới hướng dẫn siêu âm 2 bên, thuốc tê mỗi bên: $0,75 \mathrm{mg} / \mathrm{kg}$ ropivacain $0,25 \%$ rồi được lắp PCA morphine tĩnh mạch với các thông số như trên.

\section{Các thông số nghiên cứu:}

Các đặc điểm chung của đối tượng nghiên cứu: Tuổi, chiều cao, cân nặng, BMI, ASA...và các đặc điểm của gây mê hồi sức như: Liều bupivacain sử dụng, thời gian phẫu thuật.

Các tác dụng không mong muốn của hai phương pháp giảm đau: Thay đổi về hô hấp: tần số thở (lần/phút), bão hòa ôxy mao mạch $\left(\mathrm{SpO}_{2}\right)$, ức chế hô hấp (khi khó thở, tần số thở < 10 nhịp/phút hoặc thở nhanh nông. Độ bão hòa oxy giảm < 92\%); Thay đổi về tuần hoàn: mạch chậm (tần số tim < 60 lần/phút), hạ huyết áp (khi huyết áp trung bình giảm > 20\% huyết áp nền); an thần quá mức (theo thang điểm an thần chia 4 mức độ từ 0 - III); nôn, buồn nôn (chia 4 mức độ từ 0 - III); bí tiểu (chia 3 mức độ từ 0 - II); ngứa (có hoặc không).

3. Xử lý số liệu. Sử dụng phần mềm thống kê SPSS 20.0. Sự khác biệt có ý nghĩa thống kê khi $p<0,05$.

4. Đạo đức nghiên cứu. Nghiên cứu đã được thổng qua Hội đồng khoa học của Bệnh viện Phu Sản Hà Nội và đảm bảo tuân thủ các nguyên tắc về nghiên cứu y sinh học.

\section{KẾT QUẢ NGHIÊN CứU}

\section{1. Đặc điểm bệnh nhân}

Bảng 3.1. Đặc điểm của đôii tượng nghiên cứu và gây mê hồi sức

\begin{tabular}{|c|c|c|c|c|}
\hline Đặc điểm & Nhóm & $\begin{array}{c}\text { Nhóm chứng } \\
(\mathrm{n}=30)\end{array}$ & $\begin{array}{c}\text { Nhóm TAP } \\
(n=30)\end{array}$ & $\mathbf{p}$ \\
\hline \multirow{2}{*}{$\begin{array}{l}\text { Tuổi } \\
\text { (năm) }\end{array}$} & $\mathrm{X} \pm \mathrm{SD}$ & $45,33 \pm 6,23$ & $44,97 \pm 6,49$ & \multirow{2}{*}{$>0,05$} \\
\hline & Min - Max & $37-57$ & $38-53$ & \\
\hline \multirow{2}{*}{$\begin{array}{l}\text { Chiều cao } \\
\text { (cm) }\end{array}$} & $\overline{\mathrm{x}} \pm \mathrm{SD}$ & $154,6 \pm 5,21$ & $155,5 \pm 4,96$ & \multirow{2}{*}{$>0,05$} \\
\hline & Min - Max & $145-165$ & $145-163$ & \\
\hline \multirow{2}{*}{$\begin{array}{c}\text { Cân năng } \\
(\mathrm{kg})\end{array}$} & $\overline{\mathrm{x}} \pm \mathrm{SD}$ & $50,63 \pm 4,61$ & $52,33 \pm 4,85$ & \multirow{2}{*}{$>0,05$} \\
\hline & Min - Max & $42-62$ & $44-62$ & \\
\hline \multirow{2}{*}{$\begin{array}{c}\text { BMI } \\
(\mathrm{kg} / \mathrm{m} 2)\end{array}$} & $\mathrm{X} \pm \mathrm{SD}$ & $21,16 \pm 1,33$ & $21,62 \pm 1,46$ & \multirow{2}{*}{$>0,05$} \\
\hline & Min - Max & $18,18-23,68$ & $18,43-25,53$ & \\
\hline \multirow{2}{*}{ ASA } & $\mathrm{I}$ & $21(70 \%)$ & $22(73,33 \%)$ & \multirow{2}{*}{$>0,05$} \\
\hline & II & $9(30 \%)$ & $8(26,7 \%)$ & \\
\hline \multirow{2}{*}{$\begin{array}{l}\text { Bupivacain } \\
\text { (mg) }\end{array}$} & ${ }^{x} \pm S D$ & $10,12 \pm 0,83$ & $10,06 \pm 0,78$ & \multirow{2}{*}{$>0,05$} \\
\hline & Min-Max & $8-12$ & $8-12$ & \\
\hline
\end{tabular}




\begin{tabular}{|c|c|c|c|c|}
\hline \multirow{2}{*}{ Thời gian phẫu thuật (phút) } & $\mathbf{x} \pm$ SD & $71,83 \pm 10,87$ & $70,62 \pm 10,51$ & $>0,05$ \\
\cline { 2 - 5 } & Min-Max & $52-95$ & $54-92$ & $<0,05$ \\
\hline Lượng morphin tiêu thụ 24h & & $24,7 \pm 8,9$ & $16,4 \pm 6,6$ & $<0$ \\
\hline \multirow{2}{*}{ Chỉ định phẫu thuật } & U xơ tử cung & $28(93,3 \%)$ & $27(90 \%)$ & $>0,05$ \\
\cline { 2 - 5 } & Lạc nội mạc tử cung & $2(6,7 \%)$ & $3(10 \%)$ & $>0,05$ \\
\hline
\end{tabular}

Nhận xét: Không có sự khác biệt ý nghĩa thống về tuối, chiều cao, cân nặng, BMI, ASA Bupivacain, thời gian phẫu thuật giữa hai nhóm.

2. Tác dụng lên tuần hoàn, hô hấp và các tác dụng không mong muốn khác 2.1. Thay đổi liên quan đến tuần hoàn (tân số tîm và HATB)

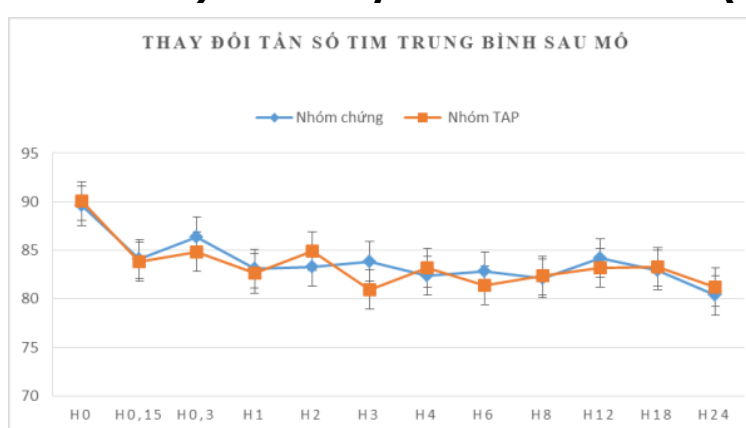

Biểu đồ 1: Thay đổi tần số tim trung bình sau mổ

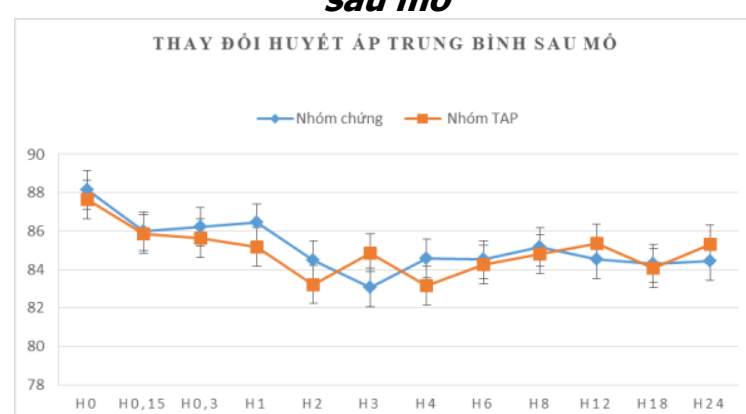

Biểu đồ 2: Thay đổi huyêt áp trung bình sau mố

Tần số tim và huyết áp trung bình của các bệnh nhân trong nghiên cứu của chúng tôi ở nhóm chứng và nhóm TAP tại tất cả các thời điểm đánh giá đều trong giới hạn bình thường. Không có khác biệt giữa 2 nhóm về tần số tim và 2.2. Thay đổi liên quan đến hô hấp (tân
số thở và $\mathrm{SpO}_{2}$ )

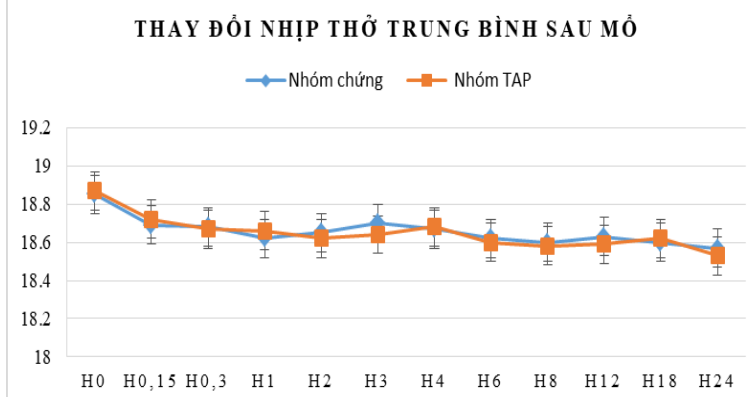

Biểu đồ 3: Thay đổi nhịp thở trung bình sau mổ

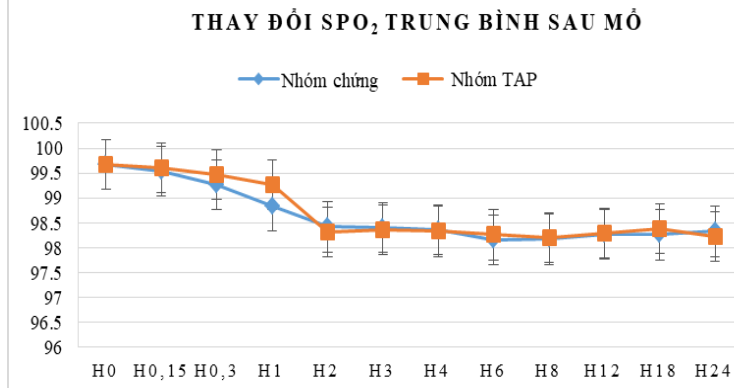

Biểu đồ 4: Thay đổi $\mathrm{SpO}_{2}$ trung binh sau mổ

Nhận xét: Không có khác biệt ý nghĩa giữa 2 nhóm về tần số thở và $\mathrm{SpO}_{2}$ trung bình ở mỗi thời điểm đánh giá $(p>0,05)$. Không gặp bệnh nhân ngừng thở hoăc có tần số thở dưới 10 lần/phút, không gặp bệnh nhân $\mathrm{SpO}_{2}<90 \%$. huyết áp trung bình ở các thời điểm đánh giá ( $p$ $>0,05)$.

2.3. Các tác dụng không mong muốn khác

\begin{tabular}{|c|c|c|c|c|}
\hline \multicolumn{2}{|c|}{$\begin{array}{l}\text { Tác dụng } \\
\text { không mong muốn khác }\end{array}$} & $\begin{array}{c}\text { Nhóm chú́ng } \\
\left(n_{1} \%\right)\end{array}$ & $\begin{array}{c}\text { Nhóm TAP } \\
\left(\mathrm{n}_{2} \%\right)\end{array}$ & $\mathbf{p}$ \\
\hline Nôn, buôn nôn & Đô I,II & $9(30 \%)$ & $4(13,33 \%)$ & $<0,05$ \\
\hline An thần & Độ I,II & $19(63,33 \%)$ & $9(30 \%)$ & $<0,05$ \\
\hline \multicolumn{2}{|l|}{ Bí tiếu } & $2(6,67 \%)$ & $2(6,67 \%)$ & $>0,05$ \\
\hline Ngứa & & $2(6,7 \%)$ & $1(3,3 \%)$ & $>0,05$ \\
\hline Ngộ độc thuốc tê & & 0 & 0 & 50 \\
\hline Tiêm thuốc vào ố bụng & & 0 & 0 & $>0,05$ \\
\hline
\end{tabular}

Nhận xét: Có sự khác biệt có ý nghĩa thống kê giữa hai nhóm về tỷ lệ nôn, buồn nôn và độ an thần mức I, II $(p<0,05)$.

\section{BÀN LUẬN}


Đặc điểm đối tượng nghiên cứu: Các đặc điểm chung của các bệnh nhân ở hai nhóm nghiên cứu của chúng tôi khá tương đồng, do đó, không ảnh hưởng đến kết quả nghiên cứu.

*Ảnh hưởng trên tuần hoàn, hô hấp: Tần số tim và huyết áp trung bình của các bệnh nhân trong nghiên cứu của chúng tôi ở nhóm chứng và nhóm TAP tại tất cả các thời điểm đánh giá đều trong giới hạn bình thường và tương đương nhau, với $\mathrm{p}>0,05$. Kết quả này cũng tương tự kết luận của $\mathrm{Fusco}^{3}$ và Bhattacharjee ${ }^{1}$ về gây tề TAP giảm đau sau mổ rất an toàn và hiệu quả với nhịp tim và huyết áp trung bình ổn định, không có sự khác biệt với nhóm chứng. Gây tê TAP không làm thay đổi huyết áp trung bình và nhịp tim của bệnh nhân.

Tần số thở và bão hòa ôxy mao mạch $\left(\mathrm{SpO}_{2}\right)$ trung bình tại các của cả 2 nhóm đều trong giới hạn bình thường. Chúng tôi không thấy khác biệt có ý nghĩa thống kê giữa hai nhóm về tần số thở cũng như $\mathrm{SpO}_{2}$ trung bình tại mỗi thời điểm đánh giá. Kết quả này cho thấy sự an toàn của gây tê TAP block cũng như sự phù hợp về liều dùng và cài đăt các thông số PCA cho các bênh nhân sau mổ. Kết quả này cũng phù hợp với nghiên cứu của các tác giả Fusco $^{3}$ và Kahsay ${ }^{4}$ cho thấy không có sự khác biệt về hô hấp giữa nhóm gây tê TAP và nhóm chứng, tất cả bệnh nhân đều có $\mathrm{Sp02}>90 \%$. Đây là ưu điểm của phương pháp TAP block vì chỉ sử dụng thuốc tê đơn thuần ở ngoại vi, do đó, không gây ảnh hưởng đến tuần hoàn, hô hấp như gây tê tủy sống hoặc gây tê ngoài màng cứng.

* Một số tác dụng không mong muốn khác. Nôn, buồn nôn là tác dụng không mong muốn thường gă̆p nhất khi sử dụng opioid tĩnh mạch, gây phiền toái, khó chịu nhất đối với bệnh nhân sau phẫu thuật. Kết quả nghiên cứu của chúng tôi cho thấy tỷ lệ nôn, buồn nôn ở nhóm chứng là $30 \%$ nhiêu hơn so với nhóm TAP là $13,33 \%$, với $p<0,05$. Kết quả chúng tôi tương tự nghiên cứu của tác giả $M c D o n n e l I^{5}$ cho thấy tỷ lệ nôn, buồn nôn của nhóm TAP giảm hơn nhiều so với nhóm chứng (69\% so với $31 \%$ ). Nghiên cứu của tác giả Bhattacharjee ${ }^{1}$ cũng thấy tỷ lệ nôn, buồn nôn ở nhóm TAP (21\%) giảm hơn đáng kể với nhóm chứng (36\%).

Tỷ lê an thần ở mức I, II (theo Chen) của nhóm TAP $(30 \%)$ thấp hơn so với nhóm chứng $(63,33 \%)$, sự khác biệt có ý nghĩa thống kê $p<0,05$. Tất cả bệnh nhân an thần ở hai nhóm đều ở mức độ I, II mức độ an thần nhẹ dễ đánh thức bằng lời nói hoặc lay gọi. Chúng tôi không gặp trường hợp nào bệnh nhẩn an thần sâu, khó đánh thức phải hỗ trợ bằng hô hấp hay xử trí bằng naloxon. Kết quả chúng tôi cũng tương tự tác giả Caney ${ }^{6}$ tỷ lệ an thần ở nhóm TAP $(37 \%)$ giảm hơn so với nhóm chứng (63\%). Tác giả Srivastava ${ }^{7}$ tỷ lệ an thần ở nhóm TAP (19\%) thấp hơn nhiêu so với nhóm chứng $(68 \%)$. Tác dụng giảm đau tốt và kéo dài của nhóm TAP giúp giảm morphin tiêu thụ, giảm tỷ lệ an thần.

Tỷ lệ ngứa trong nghiên cứu chúng tôi gặp 2 trường hợp $(6,7 \%)$ ở nhóm chứng và 1 trường hợp $(3,3 \%)$ ở nhóm TAP, sự khác biệt không có ý nghĩa thống kê với $p>0,05$. Kết quả của tác giả Belavy ${ }^{8}$ cho thấy tỷ lệ bệnh nhân ngứa ở nhóm $\operatorname{TAP}(8,7 \%)$ và nhóm chứng $(8,3 \%)$ là tương đương nhau. Tác giả Mishriky ${ }^{9}$ tỉ lệ ngứa không có sự khác biệt giữa 2 nhóm.

Bí tiểu là tác dụng không mong muốn hay găp khi sử dụng các opioid. Trong nghiên cứu của chúng tôi toàn bộ bệnh nhân đều được rút ống thông bàng quang sau mổ 6 giờ. Kết quả nghiên cứu cho thấy tỷ lệ phải đặt lại thông tiểu ở cả hai nhóm đều là $6,67 \%$, sự khác biệt không có ý nghĩa thống kê với $p>0,05$.

Trong nghiên cứu của chúng tôi, không gặp các tai biến năng nề của gây tê TAP block như: Ngộ độc thuốc tê, tiêm thuốc vào ổ bụng: Chúng tôi sử dụng thuốc ropivacain theo những khuyến cáo an toàn với liều $1,5 \mathrm{mg} / \mathrm{kg}$. Kỹ thuật tiến hành thuận lợi dưới hướng dấn của siêu âm nên không có trường hợp nào tiêm vào mạch máu hoặc tiêm ra ngoài măăt phẳng cơ ngang bụng hay vào phúc mạc. Kết quả chúng tôi cũng tương tự các nghiên cứu hiện nay với gây tê TAP dưới hướng dẩn siêu âm cho thấy những biến chứng rất hiếm gặp.

\section{KẾT LUẦN}

Gây tê mặt phẳng cơ ngang bụng (TAP block) hai bên bằng ropivacain $0,25 \%$, dưới hướng dẫn của siêu âm để giảm đau sau mổ cắt tử cung hoàn toàn đường bụng không ảnh hưởng đến tuần hoàn, hô hấp của bệnh nhân nhưng làm giảm tỷ lệ nôn, buồn nôn và tỷ lệ an thần độ $\mathrm{I}$, độ II so với nhóm chứng (Tỷ lệ nôn, buồn nôn và tỷ lệ an thần của hai nhóm là $13,33 \%$ và $30 \%$ so với $30 \%$ và $63,3 \% ; p<0,05)$.

\section{TÀl LIẸU THAM KHẢO}

1. Bhattacharjee S, Ray M, Ghose T, Maitra S, Layek A. Analgesic efficacy of transversus abdominis plane block in providing effective perioperative analgesia in patients undergoing total abdominal hysterectomy: A randomized controlled trial. J Anaesthesiol Clin Pharmacol. 2014;30(3):391. doi:10.4103/0970-9185.137274 
2. Nguyễn Thế Lộc, Nguyễn Đức Lam. Nghiên cứu hiệu quả của phương pháp gây tê tủy sông và ngoài màng cứng phối hợp để mổ và giảm đau sau mổ cắt tử cung hoàn toàn tại bệnh viện phụ sản trung ương. Tap chí y học thực hành. 2016;1015:218-220.

3. Fusco $\mathbf{P}$, Cofini $\mathbf{V}$, Petrucci $E$, et al. Transversus Abdominis Plane Block in the Management of Acute Postoperative Pain Syndrome after Caesarean Section: A Randomized Controlled Clinical Trial. Pain Physician. 2016;19(8):583-591.

4. Kahsay DT, Elsholz W, Bahta HZ. Transversus abdominis plane block after Caesarean section in an area with limited resources. Southern African Journal of Anaesthesia and Analgesia. 2017;23(4):90-95. doi:10.1080/22201181.2017.1349361

5. McDonnell JG, O'Donnell BD, Curley G, Heffernan A, Power C, Laffey JG. The Analgesic Efficacy of Transversus Abdominis Plane Block After Abdominal Surgery: A Prospective Randomized Controlled Trial: Anesthesia \& Analgesia. 2007;104(1):193-197. doi:10.1213/ 01.ane.0000250223.49963.0f
6. Carney J, McDonnell JG, Ochana A, Bhinder R, Laffey JG. The Transversus Abdominis Plane Block Provides Effective Postoperative Analgesia in Patients Undergoing Total Abdominal Hysterectomy. Anesthesia \& Analgesia. 2008;107(6):2056-2060. doi:10.1213/ane.0b013e3181871313

7. Srivastava U, Verma S, Singh TK, et al. Efficacy of trans abdominis plane block for post cesarean delivery analgesia: A double-blind, randomized trial. Saudi Journal of Anaesthesia. 2015;9(3):298. doi:10.4103/1658-354X.154732

8. Belavy D, Cowlishaw PJ, Howes M, Phillips F. Ultrasound-guided transversus abdominis plane block for analgesia after Caesarean delivery. British Journal of Anaesthesia. 2009;103(5):726-730. doi:10.1093/bja/aep235

9. Mishriky BM, George RB, Habib AS. Transversus abdominis plane block for analgesia after Cesarean delivery: a systematic review and meta-analysis. Can J Anaesth. 2012;59(8):766778. doi:10.1007/s12630-012-9729-1

\section{TỔNG QUAN NGHIÊN CỨU ỨNG DUUNG TRÍ TUÊ NHÂN TAO TRONG CHẨN ĐOÁN UNG THƯ VÚ BẰNG ẢNH GIẢI PHẪU BÊ̂NH KỸ் THUÂTT Số}

Đào Văn Tú, Nguyễn Khắc Dũng, Bùi Thị Oanh, Nguyễn Lê Hiệp, Vũ Đức Hoàn, Đặng Hữu Dũng, Nguyễn Văn Chủ, Bùi Văn Giang, Tạ Văn Tờ(*)

\section{TÓM TẮT}

Ung thư vú là bênh ung thư phổ biến nhất trên nữ giới và là nguyên nhân gây tử vong hàng đâu do ung thư trên toàn thế giới. Cơ sở chính để điều trị ung thu vú là chẩn đoán mô bệnh học, việc chẩn đoán này quyết đinh hướng điều trị và tiên lượng bênh. Những tiến bộ trong trí tuệ nhân tạo (AI) cùng với việc vận dung giải phâu bệh kỹ thuẩt số đã đưa ra một cách tiếp cận đầy hứa hẹn trong việc chẩn đoán, phân loaiung thư vú, đáp ứng được nhu câu trong thực tế lâm sàng. Trong bài viêt này, chúng tôi tổng quan về ứng dung AI trong chẩn đoán ung thư vú dưa trên ảnh kỹ thuật số hóa giải phẫu bệnh, đồng thời phác thảo những tiềm năng ứng dụngtại Việt Nam.

Tư khóa: Ung thư vú, trí tuệ nhân tạo, ảnh giải phẫu bệnh

\section{SUMMARY \\ OVERVIEW OF APPLICATION RESEARCH OF ARTIFICIAL INTELLIGENCE ON BREAST CANCER DIAGNOSIS BASED ON DIGITAL}

\section{(*)Bênh viên $K$}

Chịu trách nhiệm chính: Đào Văn Tú Email: vantu.dao@bvk.org.vn

Ngày nhận bài: 29.12.2020

Ngày phản biên khoa hoc: 22.2.2021

Ngày duyệt bài: 1.3 .2021

\section{PATHOLOGY IMAGES}

Breast cancer is the most common cancer in women and the leading cause of cancer deaths worldwide. The essential basisfor breast cancer treatment is histopathology, which determines the direction of treatment and prognosis of the disease. Advances in artificial intelligence (AI) together with the use of digital pathology have presented a promising approach in breast cancer diagnosis and classification, meeting the real needs clinical practice. In this article, we provide an overview of AI applications in breast cancer diagnostics based on digital pathology images of the disease, and proposethe potentials in application in Vietnam.

Keywords: Breast cancer, artificial interligence, pathology image

\section{I. ĐĂT VẤN ĐỀ}

Ung thư vú là một trong những bệnh ung thư phổ biến nhất được chẩn đoán ở phụ nữ trên toàn thế giới và nó là nguyên nhân chính gây tử vong ở phụ nữ. Ở các nước thu nhập thấp và thu nhập trung bình, tỷ lệ tử vong tương đối cao so với các quốc gia phát triển. Theo báo cáo năm 2018 của Tổ chức Nghiên cứu Quốc tế về Ung thư (IARC), hơn 2 triệu phụ nữ trong năm 2018 được chẩn đoán mắc bênh ung thư vú trên toàn thế giới. Đây được coi là khoảng $11,6 \%$ của tất 